\title{
Influence of delivery and feeding mode in oral fungi colonization - a systematic review
}

\author{
Maria Joao Azevedo ${ }^{1,2,3,4}$, Maria de Lurdes Pereira ${ }^{1,5}$, Ricardo Araujo ${ }^{2,3,6}$, Carla Ramalho ${ }^{3,7,8}$, Egija Zaura ${ }^{4}$ and \\ Benedita Sampaio-Maia ${ }^{1,2,3, *}$ \\ 1 Faculdade de Medicina Dentária, Universidade do Porto, Portugal. \\ 2 INEB - Instituto Nacional de Engenharia Biomédica, Universidade do Porto, Portugal. \\ 3 i3S - Instituto de Investigação e Inovação em Saúde, Universidade do Porto, Portugal. \\ ${ }^{4}$ Academic Center for Dentistry Amsterdam (ACTA), University of Amsterdam and Vrije Universiteit Amsterdam, the Netherlands. \\ ${ }^{5}$ EpiUnit- Instituto de Saúde Pública, Universidade do Porto. \\ ${ }^{6}$ Dept. Medical Biotechnology, College of Medicine and Public Health, Flinders University of South Australia. \\ ${ }^{7}$ Faculdade de Medicina, Universidade do Porto, Portugal. \\ ${ }^{8}$ Centro Hospitalar São João, Porto, Portugal. \\ * Corresponding Author: \\ Benedita Sampaio-Maia, Phone: +351 22090 1100; E-mail: bmaia@fmd.up.pt
}

\begin{abstract}
Postnatal acquisition of microorganisms from maternal and environmental sources contributes to the child microbiome development. Several studies showed that the mode of delivery and breastfeeding may have impact on the oral bacterial colonization, however, the influence on oral fungal colonization is still unknown. We performed a systematic literature review on mother to child oral fungi transmission, namely regarding the association between the mode of delivery and breastfeeding in oral yeast colonization. Our analysis revealed no significant differences between the oral mycobiome of breastfed and bottle-fed children. As for the delivery mode, the majority of studies found a relation between fungal colonization and vaginal delivery. Candida albicans was the most commonly isolated fungi species. Our analysis suggests that maternal breastfeeding does not seem to influence oral mycology, but vaginal delivery appears to promote oral yeast colonization in early life.
\end{abstract}

doi: $10.15698 / \mathrm{mic} 2020.02 .706$

Received originally: 25.07.2019,

in revised form: 19.11.2019,

Accepted 02.12.2019,

Published 07.01.2020.

Keywords: oral fungi, delivery mode, feeding mode, oral colonization, yeasts, Candida, mycobiome.

\section{Abbreviations:}

C-section - caesarean-section

\section{INTRODUCTION}

The human microbiome is a complex ecosystem that varies considerably throughout the body and among individuals $[1,2]$. Several factors are known to modulate the development of the infant microbiome, namely host genetics, prenatal environment, delivery mode and postnatal factors, such as antibiotics, environment or diet [3]. It is now known that the maturation of the human microbiome and its homeostasis with the human body might have longterm consequences for health [4].

The microorganisms residing in the oral cavity, and their inevitable inter-relationships, are essential components in changing the balance between health and disease, not only locally but also systemically $[5,6]$. From an early stage in life, the human oral cavity comes in contact with a wide variety of microorganisms, and the set of initial colonizers seems to condition the subsequent colonization. These early microbial communities have therefore a major role in the constitution and organization of the adult microbiome and may represent a source of both pathogenic and protective microorganisms in a very early stage of human life.

During delivery there is a significant transmission of microorganisms from the mother to the new-born $[3,7,8]$. This "maternal inoculation" is considered a critical component for the development of infant microbiome [8]. Deliv- 
ery mode affects significantly the type of transmitted microorganisms; different body sites of children born through vaginal delivery present, five min after birth, bacterial communities similar in composition to vaginal communities, while children born by caesarean-section (C-section) have bacterial communities similar to skin microbiota of mother [7]. The influence of the type of delivery on the establishment of the oral microbiota of the child has yet to be clarified. Holgerson et al. [9] showed in healthy three-monthold infants that vaginally delivered infants presented significantly more oral bacterial taxa than infants delivered by Csection, however Chu et al. [10] did not find discernible differences in oral community structure or function between six-weeks infants born by C-section or vaginally. Some studies, investigating whether mode of delivery is associated with Mutans streptococci colonization during infancy also found contradictory results [11-14].

Following the delivery mode, the feeding habit may also represent a significant source of oral microorganisms and constitute a microbiome modulator. Breast milk contains bioactive substances that boost microbial colonization and the development of the immune system, as well as growth factors that influence the colonization and maturation of bacteria in the intestinal mucosa [15-17]. Thus, this nourishment imposes itself as one of the most important elements in the postpartum metabolic modulation and immunological programming related to the health of the child [16]. Breast milk includes oral bacteria such as those belonging to Streptococcus and Staphylococcus [18], with significant increase of Veillonella, Prevotella and Leptotrichia within one to six months after delivery [16]. Accordingly, high amounts of Streptococcus spp. were found in both the mother's milk and the infant's saliva $[19,20]$. Also, it was shown that the salivary microbiota of threemonth-old infants differ among infants exclusively breastfed or fed with artificial milk [21]. Interestingly, a metaanalysis of cross-sectional studies showed that breastfed children are less susceptible to caries than infants fed with artificial milk, suggesting that breastfeeding may protect against dental caries during childhood [22]. Despite this fact, the influence of the feeding mode in the establishment of the gut microbiome is vastly more studied than in the oral microbiome $[23,24]$.

Although a minority in the oral cavity, fungi play a key role in regulating a healthy balance between microbes and the host by being involved in a wide panoply of chemical, physical and metabolic microenvironment-dependent interactions; for this reason, they are considered a potential "keystone species" $[25,26]$. One of the most studied interkingdom interaction is between fungi and bacteria, with symbiotic polymicrobial biofilms reportedly found in oral dysbiosis such as caries, periodontitis, endodontic infections, angular cheilitis and denture stomatitis [5, 27-29]. This symbiotic relation allows, for instance, the presence of bacteria in the mucosa due to the fungal ability of adhering to mucosa, decreases bacterial susceptibility against antibiotic treatment, as shown for Staphylococcus aureus and Candida albicans, and, additionally, accelerates the recovery of some dominant bacterial species after antimicrobial treatment, as observed in murine models, promoting bacterial resilience $[5,27,30]$. Additionally, it is known that C. albicans has the ability of changing its microenvironment, either by influencing its physical properties, such as $\mathrm{pH}$, or by producing secondary metabolites, allowing a selective growing of certain bacterial species and the suppression of some virulence factors, such as the ones produced by Streptococcus mutans [25]. Compared to the bacterial component of the microbiota, the mycobiome is poorly studied, perhaps due to the following facts: i) fungi are present in a significantly lower proportion than bacteria, ii) it is difficult to isolate their genetic material and iii) many species are still uncultivable using current methods [26]. In the oral cavity of a healthy individual more than 75 genera of fungi have been found, with the most prevalent being Candida, Cladosporium, Aureobasidium, Aspergillus and Malassezia spp. [26, 31-34].

Due to the importance of fungi in the oral ecosystem and the lack of knowledge about the acquisition and maturation of the oral mycobiome, the purpose of this study was to perform a systematic literature review on the influence of the type of nourishment and the delivery mode on fungal transmission between mother and infant.

\section{SYSTEMATIC REVIEW}

The search was performed using PubMed database, from April 25 to June 18, 2019. The following combinations of key words were used:

a) (delivery $O R$ cesarean section $O R$ vaginal delivery) AND (yeast OR fungal transmission OR Candida OR fungi OR mycobiota OR mycobiome) AND (infants OR children OR newborn OR neonate OR baby)

b) (feeding mode OR breastfeeding OR bottle feeding) AND (yeast OR fungal transmission OR Candida OR fungi OR mycobiota OR mycobiome) AND (infants OR children OR newborn OR neonate OR baby).

The inclusion criteria used in this systematic review were comparative studies in healthy humans and written in English, related to oral fungi transmission and acquisition. The studies selected must investigate the type of nourishment and delivery mode in relation to the acquisition of the fungi. Both longitudinal studies and cross-sectional studies were included and no restrictions were applied regarding the date of publication of the studies. Systematic reviews were excluded, as also studies regarding exclusively bacteria and virus transmission. Additionally, studies that did not test associations between fungi transmission and the type of delivery or nourishment were excluded. Research papers concerning the use of probiotics and antibiotics in the peri-natal period were not considered, neither studies that did not explore the oral mycobiome.

After the search in PubMed, a total of 6881 papers were retrieved from the query (see Figure 1). From this list of scientific papers, titles and abstracts were screened of which 22 papers [35-56] made the final list, after removing duplicated articles. Only 14 articles of these were finally considered suitable for this review [35, 37-39, 41, 42, 44, $46,50,51,53-56]$, since six articles did not test associations 
between type of delivery/type of nourishment with the oral mycobiome [36, 40, 43, 45, 48, 52] and two articles did not explore the oral mycobiome $[47,49]$.

Concerning the type of study, seven of the selected articles were cross-sectional studies [35, 41, 44, 46, 50, 54, $56]$ and seven were longitudinal studies [37-39, 42, 51, 53, 55].

Regarding the objective of the selected papers, two focused on the colonization in very low weight newborns [37, 38]; one study investigated newborns fungal colonization in intensive care units [55]; one article investigated the interaction between fungi and Helicobacter pylori in early colonization [50]; two articles specifically investigated vertical transmission of fungi from mother to child [39, 42]; one article investigated the possibility of an association between the presence of yeasts and the use of pacifiers in children among other factors such as the type of delivery [56]; five articles focused only on the fungal colonization of the mouth of infants in relation with the feeding mode [35, $41,44,46,54]$; an article tried to find associations between environmental factors and oral fungi colonization on infants [51]; and one paper investigated the evolution of the mycobiome across body sites during the first month of life [53].

The majority of the articles selected used swabs from the oral sites or saliva. With respect to the time points of collection in the longitudinal studies regarding to the infants, these ranged from within 24 hours after delivery to one year. Tables 1 and $\mathbf{2}$ sum up information with respect to the reference number, samples and number of participants, percentage of children carriers of oral fungi who were breastfed/bottle-fed or born by C-section/ vaginal delivery in each study, methodology used to identify fungi and the highlights of the results of each study.

\section{FEEDING MODE}

The literature about the relation between the feeding mode and the oral mycobiome is controversial. From the selected five cross-sectional studies that explored this association, three concluded that there was no difference in the oral mycobiome between the children who were breastfed and children who were bottle-fed. Darwazeh et al. [41] studied 206 infants aged from two to eleven months old. There were no significant differences in the frequency of Candida species isolation or density of Candida spp. growth between infants who were breastfed, bottle-fed or who were on both patterns of feeding ( $p=$ 0.14), leading them to conclude that Candida spp. are commensals of the oral microbiota and independent of the feeding mode. However, a significantly higher frequency of Candida spp. isolates was observed from infants who suck pacifiers compared to those who did not $(p<0.05)$. In accordance with this previous study, a research conducted by Matee et al. [46], where swabs from tongue and buccal mucosa were collected from 200 infants (age between six months and two years), demonstrated no specific pattern between the predominant biotypes of $C$. albicans and breastfeeding. The authors admit that results may be due

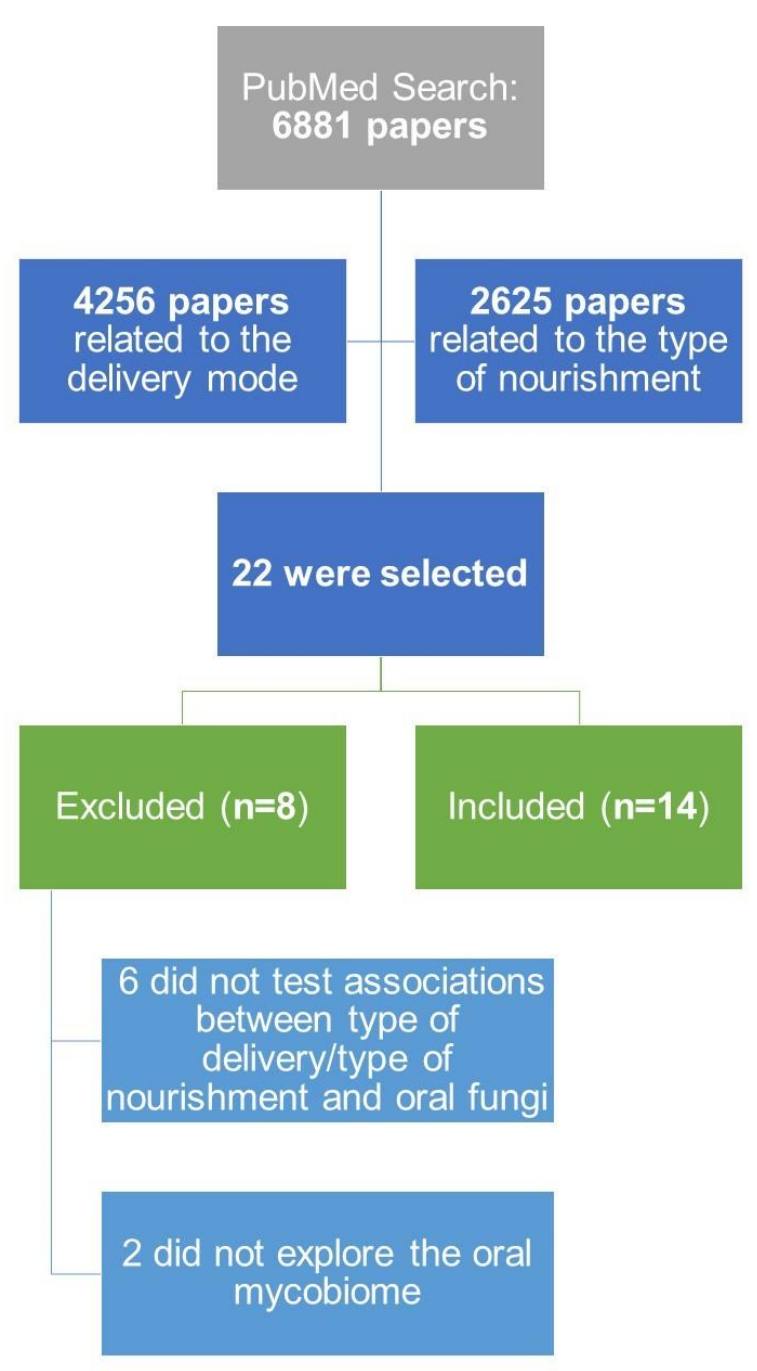

FIGURE 1: Workflow overview of the systematic review.

to a small number of biotype clusters used in the study (a total of five) and to the small cohort studied. Additionally, Mattos-Graner et al. [56] studied the presence of oral yeasts in a group of 36 children, aged from one to eight months. They described the presence of yeast colonization in $58.3 \%$ of the infants and a notorious $15 \%$ increase in the frequency of yeasts among children who were never breastfed/only breastfed until two months of age, when compared to those who were breastfed for a longer period. Notwithstanding, no significant differences between the duration of breast-feeding and the frequency of yeasts in the infants were reported $(p<0.05)$, with the only significant factor related to yeasts being the use of pacifier. A more recent study by Neves et al. [35] studied saliva (instead of oral swabs) from 14 infants from two to four years grouped into children with or without early childhood caries. It concluded there were no differences in the total Candida spp. count between children who were either breast- or bottle-fed $(p=0.184)$. Also, the total number of Candida spp. was not influenced by the use of pacifier ( $p=$ 0.286). Finally, a study by Stecksen-Blicks et al. [51] found 
TABLE 1. Studies regarding the relation between the feeding mode and the oral mycobiome.

\begin{tabular}{|c|c|c|c|c|c|c|}
\hline Samples & No. participants & $\%$ Breast-fed & \% Bottle-fed & Methods & Major Findings & Ref. \\
\hline $\begin{array}{l}\text { Swabs from tongue } \\
\text { and right buccal muco- } \\
\text { sa of the infants. }\end{array}$ & 200 infants & N.A. & N.A. & $\begin{array}{l}\text { Culture in SAB; } \\
\text { Identification by systems API ZYM and API 20C AUX and } \\
\text { Boric Acid resistance test }\end{array}$ & $\begin{array}{l}\text {-) No specific pattern between the predominant Candida } \\
\text { biotypes and breast feeding. }\end{array}$ & [46] \\
\hline $\begin{array}{l}\text { Swabs from the dor- } \\
\text { sum of the tongue, } \\
\text { buccal mucosae and } \\
\text { palate of the infants. }\end{array}$ & 206 infants & $52.9 \%$ & $4.8 \%$ & $\begin{array}{l}\text { Culture on SAB agar; } \\
\text { Identification by germ-tube test and yeast identification } \\
\text { system Microring YT; } \\
\text { Scored as: }<10 \text { colonies = mild; } 11-50 \text { colonies = moder- } \\
\text { ate growth; }>50 \text { colonies = heavy growth }\end{array}$ & $\begin{array}{l}\text {-) No significant differences in the frequency of Candida } \\
\text { isolation or density of growth between infants who were } \\
\text { breast-fed, bottle-fed or on both patterns of feeding ( } p= \\
0.14 \text { ); } \\
\text {-) Significantly higher frequency of Candida spp. isolation } \\
\text { from infants who suck pacifiers compared to those who did } \\
\text { not }(p<0.05) \text {. }\end{array}$ & [41] \\
\hline $\begin{array}{l}\text { Swabs from oral muco- } \\
\text { sa of cheek, edentulous } \\
\text { ridge, dorsum of the } \\
\text { tongue and hard palate } \\
\text { of the infants }\end{array}$ & 36 infants & $\begin{array}{c}0-2 \text { months: } \\
67.31 \% \\
>2 \text { months: } \\
15.25 \%\end{array}$ & $47.08 \%$ & $\begin{array}{l}\text { Culture on SAB agar with chloramphenicol (10\%); } \\
\text { Replication of some cultures on SAB agar; } \\
\text { Pure cultures analyzed for specific identification. }\end{array}$ & $\begin{array}{l}\text {-) Yeasts were detected in } 58.3 \% \text { of the children; } \\
\text {-) Children who were never breast-fed/breast-fed until two } \\
\text { months of age had } 15 \% \text { higher frequency of oral yeasts } \\
\text { compared to those who were breast-fed for a longer time; } \\
\text {-) No significant association was observed between the } \\
\text { prevalence of yeast infection and bottle-feeding; } \\
\text {-) The use of a pacifier influenced the colonization and pro- } \\
\text { liferation of yeasts in the oral cavity. }\end{array}$ & [56] \\
\hline $\begin{array}{l}\text { Tongue swabs from the } \\
\text { infants and their moth- } \\
\text { ers; swabs from the } \\
\text { skin of the women's } \\
\text { nipples and areolae. }\end{array}$ & $\begin{array}{l}169 \text { women and } \\
85 \text { infants }\end{array}$ & $4.71 \%$ & $35.29 \%$ & $\begin{array}{l}\text { Culture on SAB agar with chloramphenicol; } \\
\text { Identification by considering germ tube production in } \\
\text { sterile rabbit serum, the formation of chlamydospores, } \\
\text { hyphae and yeasts in corn meal Tween } 80 \text { agar, carbo- } \\
\text { hydrate assimilation and fermentation }\end{array}$ & $\begin{array}{l}\text {-) Significant differences in the prevalence of Candida spp. } \\
\text { related with the feeding mode: } 34.55 \% \text { in breast-fed infants' } \\
\text { mouths and in } 66.67 \% \text { of those who were bottle-fed, sug- } \\
\text { gesting a protector role of breastmilk ( } p<0.05 \text { ). }\end{array}$ & [54] \\
\hline $\begin{array}{l}\text { Swabs from dorsal } \\
\text { surface of the tongue } \\
\text { and mid-palate of the } \\
\text { infants }\end{array}$ & 300 infants & N.A. & N.A. & $\begin{array}{l}\text { Culture in SAB medium; } \\
\text { Identification by germ-tube test, chlamydospore for- } \\
\text { mation on corn meal agar and API 20C AUX system. }\end{array}$ & $\begin{array}{l}\text {-) Differences }(p<0.01) \text { in the prevalence of Candida spp. } \\
\text { carriage between children who were breast-fed and bottle- } \\
\text { fed or other fluids and children who were only breast-fed. }\end{array}$ & [44] \\
\hline Saliva from the infants. & 14 infants & N.A. & N.A. & ChromAgar for analyzing colonies of Candida spp. & $\begin{array}{l}\text {-No difference in the total Candida spp. count between chil- } \\
\text { dren who are breast/bottle fed and those who are not } \\
(\mathrm{p}=0.184) \text {. }\end{array}$ & {$[35]$} \\
\hline
\end{tabular}

NA - Information not available in the paper.

$\mathrm{SAB}$ - Sabouraud dextrose medium

a Percentage of breast-fed children carriers of oral fungi.

b Percentage of bottle-fed children carriers of oral fungi. 
TABLE 2. Studies regarding the relation between the delivery mode and the oral mycobiome.

\begin{tabular}{|c|c|c|c|c|c|c|}
\hline Samples & No. participants & $\%$ C-section ${ }^{a}$ & $\%$ Vaginally & Methods & Major Findings & Ref. \\
\hline $\begin{array}{l}\text { Swabs from oropharynx, groin, } \\
\text { rectum, perineum and endotra- } \\
\text { cheal tube aspirate andurine of } \\
\text { the infants; Breastmilk from the } \\
\text { mothers. }\end{array}$ & 146 infants & $23.1 \%$ & 76.9\% & $\begin{array}{l}\text { Culture on } \mathrm{SAB} \text { agar; } \\
\text { Identification by germ tube production and by sucrose assimilation } \\
\text { tests; } \\
\text { Germ negative tubes were identified by Uni-Yeast Tek Wheel }\end{array}$ & $\begin{array}{l}\text {-) Significantly more infants with colonization were delivered vaginally com- } \\
\text { pared with the infants without colonization }(p<0.05) \text {. }\end{array}$ & [37] \\
\hline $\begin{array}{l}\text { Swabs from cheek, lip and } \\
\text { mouth pavement of the neo- } \\
\text { nates; Vaginal secretion of the } \\
\text { mothers. }\end{array}$ & $\begin{array}{l}100 \text { mother-infant } \\
\text { pairs }\end{array}$ & $28 \%$ & $72 \%$ & $\begin{array}{l}\text { Culture on SAB agar; } \\
\text { Phenotypical profiling by susceptibility to killer toxins; proteinase } \\
\text { research; phospholipase research; serotyping; antifungal suscepti- } \\
\text { bility; } \\
\text { Genotyping profiling by RAPD-PCR Reaction. }\end{array}$ & $\begin{array}{l}\text {-) Frequencies of yeast isolation from oral mucosa were } 25 \% \text { and } 3.6 \% \text {, in cases } \\
\text { of vaginal and cesarean births. }\end{array}$ & [39] \\
\hline $\begin{array}{l}\text { Oral and rectal swabs and tra- } \\
\text { cheal aspirates (collected with } \\
\text { sterile traps) from infants. }\end{array}$ & 593 neonates & $43.23 \%$ & $56.76 \%$ & $\begin{array}{l}\text { Culture on SAB agar with } 50 \mathrm{mg} / \mathrm{mL} \text { chloramphenicol and } 50 \mathrm{mg} / \mathrm{mL} \\
\text { gentamicin; } \\
\text { Identification by germ tube formation and ChromAgar Candida test, } \\
\text { Mycotube test and API ID } 32 \mathrm{C} \text {. }\end{array}$ & $\begin{array}{l}\text {-) Fungal colonization occurred more frequently in neonates born vaginally than } \\
\text { in those born after } \mathrm{C} \text {-section }(p=0.053) \text {; } \\
\text {-) The mouth was the second most frequent site of colonization after the rec- } \\
\text { tum; } \\
\text {-) Vaginal delivery was the only factor to significantly increase the risk for early } \\
\text { fungal colonization in neonates. }\end{array}$ & [55] \\
\hline $\begin{array}{l}\text { Oral, rectal, and inguinal sam- } \\
\text { ples from infants; maternal } \\
\text { vaginal, rectal, hand and oral } \\
\text { swabs. }\end{array}$ & $\begin{array}{l}76 \text { mother-infant } \\
\text { pairs }\end{array}$ & $51 \%$ & $49 \%$ & $\begin{array}{l}\text { C. albicans isolates were identified by germ tube production. The } \\
\text { rest of the isolates were further identified by the RapidID yeast plus } \\
\text { system. } \\
\text { Southern Blot Analysis of the isolates, after purification. }\end{array}$ & $\begin{array}{l}\text {-) Infants born vaginally rather than by C-section were at increased risk for early } \\
\text { colonization ( } p=0.009 \text { ); } \\
\text {-) Among all C. albicans colonized infants, } 41 \% \text { acquired the organism from the } \\
\text { mother by vertical transmission. }\end{array}$ & [38] \\
\hline $\begin{array}{l}\text { Swabs from the oral cavity of } \\
\text { the newborns and oral and } \\
\text { vaginal swabs from the mothers. }\end{array}$ & $\begin{array}{l}347 \text { mother-infant } \\
\text { pairs }\end{array}$ & $48.15 \%$ & $51.85 \%$ & $\begin{array}{l}\text { Culture on YeastGlucose Chloramphenicol (YGC) agar; } \\
\text { Pure cultures of yeasts were identified as Candida spp, using Chro- } \\
\text { mAgar. }\end{array}$ & $\begin{array}{l}\text {-) The majority of colonized neonates were born vaginally; } \\
\text {-) Large quantity of oral C. albicans colonies in newborns may suggest correla- } \\
\text { tion between Candida colony counts in the vagina of mother and Candida } \\
\text { colonization in the neonate; } \\
\text {-) The only Candida species isolated was C. albicans; } \\
\text {-) All colonized neonates had the same pulsotype of } C \text {. albicans as their moth- } \\
\text { ers. }\end{array}$ & [50] \\
\hline $\begin{array}{l}\text { Swabs from the infants' oral and } \\
\text { rectal mucosa; swabs from the } \\
\text { mothers' vaginal mucosa. }\end{array}$ & $\begin{array}{l}108 \text { mothers and } \\
89 \text { neonates }\end{array}$ & $18.73 \%$ & $81.27 \%$ & $\begin{array}{l}\text { Culture on SAB agar; } \\
\text { Identification with API } 20 \text { CAUX system; } \\
\text { Antifungal susceptibility testing by the E-test method. }\end{array}$ & $\begin{array}{l}\text {-) Statistically significant differences between the frequency of oral yeasts } \\
\text { isolated from normally-delivered neonates compared to the cesarean group ( } p \\
=0.0063 \text { ). }\end{array}$ & [42] \\
\hline $\begin{array}{l}\text { Swabs from cheeks and the } \\
\text { tongue of the neonates; venous } \\
\text { blood }(10 \mathrm{ml} \text { ) and breastmilk (10 } \\
\text { ml) from mother. }\end{array}$ & $\begin{array}{l}100 \text { mother- } \\
\text { offspring pairs }\end{array}$ & $11 \%$ & $89 \%$ & $\begin{array}{l}\text { Samples were cultivated on a selective media Oricult- } N \text { semi- } \\
\text { quantitative dipslide and scored } 0=\text { no growth; } 1=10^{3} \mathrm{CFU} \mathrm{ml}^{-1} ; 2= \\
10^{4} \mathrm{CFU} \mathrm{ml}^{-1} ; 3=10^{5} \mathrm{CFU} \mathrm{ml}^{-1}\end{array}$ & $\begin{array}{l}\text {-) Delivery mode was not associated with colonization of the child at four } \\
\text { weeks of age }(p>0.05) \text {. Colonization was fairly stable until six months of age. } \\
\text { Exposure to furry pets and siblings impacted oral Candida. }\end{array}$ & [51] \\
\hline $\begin{array}{l}\text { Swabs from the oral mucosa, } \\
\text { forehead, and anal cavity of } \\
\text { infants; swabs from vaginal and } \\
\text { anal sites of mothers. }\end{array}$ & $\begin{array}{l}17 \text { infants and } 16 \\
\text { mothers }\end{array}$ & $58.82 \%$ & $41.18 \%$ & $\begin{array}{l}\text { DNA extraction with Mo Bio Powersoil kit; amplification of the IT2 } \\
\text { region by PCR (with modifications), followed by their purification; } \\
\text { sequencing with Illumina MiSeq system. }\end{array}$ & $\begin{array}{l}\text {-) For oral mycobiomes, birth mode did not significantly impact the alpha diver- } \\
\text { sity trajectory over time (caesarean section } \mathrm{p}=0.238 \text {; vaginal } \mathrm{p}=0.873 \text { ) or beta } \\
\text { diversity clustering }(\mathrm{p}=0.261) \text {; } \\
\text {-) Caesarean section-born infants have a significantly higher relative abundance } \\
\text { of Candida orthopsilosis than infants born vaginally }(\mathrm{p}=0.001) \text {. }\end{array}$ & [53[ \\
\hline
\end{tabular}

NA - Information not available in the paper.

$\mathrm{SAB}$ - Sabouraud dextrose medium

a Percentage of children born by C-section carriers of oral fungi.

b Percentage of children born vaginally carriers of oral fungi. 
that the oral Candida colonization was between 11 to $15 \%$ during the first year of life, remaining fairly stable during the first six months. These authors concluded that breastfeeding duration was not associated with oral Candida colonization of the child.

Contrarily to these previously mentioned results, a research by Zöllner and Jorge [54] found a significant difference in the prevalence of Candida in relation with the feeding mode. In this investigation, they sampled tongue swabs from the infants and from their mothers and also swabs from the skin of the women's nipples and areolae ( $N=169$ women and 85 infants, aged from one to five months). Their results showed oral fungal colonization in $34.6 \%$ of the breastfed infants (who did not use pacifiers or any other kind of rubber nipples) versus $66.7 \%$ of the exclusively bottle-fed ones $(p<0.05)$. Moreover, in $81.81 \%$ of cases, the Candida species coincided in the mouth of the infant and on the breast of the mother, suggesting a transmission between mother breast and child oral cavity or vice versa. Also, there was a higher prevalence of Candida spp. on the breast nipple and areolae samples of lactating women than in non-lactating women $(p<0.05)$, explained by moistened, macerated and exposed to constant trauma breast surface that potentiate fungi colonization. The lower oral fungi colonization on breastfed than on non-breastfed children was explained by the authors due to resistance factors present in the breastmilk that may play a protective role in the oral ecosystem of the infant against microorganisms from Candida genus. Furthermore, Kadir et al. [44] in a cross-sectional study including 64 infants (ages from zero to two years), found significant differences $(p<0.01)$ in the prevalence of candidal carriage between diet groups of Turkish children: $18.5 \%$ of children who received breast milk and bottle milk or other fluids were colonized and none of the children who were exclusively breastfed were colonized. The presence of Candida was found particularly in children who were fed both breast and bottle milk or fluids sweetened with carbohydrates.

Of notice is that all these studies used classic cultural method for fungi detection, supposedly having similar sensitivities.

\section{DELIVERY MODE}

The relationship between the delivery mode and oral fungi colonization was less controversial and several studies demonstrated this influence.

Firstly, a study by Baley et al. [37] ( $\mathrm{N}=146$ very low birth weight infants) identified fungi in $26.7 \%$ of the very low birth weight infants. The researchers concluded that significantly more infants with fungal colonization were delivered vaginally compared with the infants without colonization ( $p<0.05)$. Farmaki et al. [55] collected during a twelvemonth period and on a weekly basis, oral and rectal swabs, as well as tracheal aspirates, from 593 neonates admitted in a neonatal intensive care unit. Oral colonization was reported in 46 out of 72 colonized neonates. They concluded that fungal colonization occurred $10 \%$ more in neonates born vaginally than in those born after
C-section ( $p=0.053)$ and that vaginal delivery was the only significant risk factor for early colonization. A late colonization may occur due to longer stays in the neonate intensive care unit. Interestingly, very-low birth weight neonates were more frequently colonized by non-albicans Candida spp. than neonates with birthweight above 1,500 g, who were mostly colonized by $C$. albicans. In accordance with this study, an investigation by Caramalac et al. [39] revealed that the frequencies of yeast isolation from oral mucosa were $25 \%$ and $3.6 \%$, in cases of vaginal and cesarean deliveries, respectively. This study was conducted by sampling swabs from mother's oral cavity and vagina, and cheek, lip and the floor of the mouth swabs from the neonates ( $N=100$ pairs), after which they were submitted to phenotyping and genotypic profiling by RAPD-PCR reaction. The authors suggest that vaginal delivery may lead to fungal colonization in neonates, not only due to the direct contact with the vaginal mucosa but also due to the trauma suffered by the newborn while passing through the birth canal, because the results revealed that in only two cases mother and son shared the same genotypic profile of the isolated yeasts. Moreover, Bliss et al. [38] gathered a group of 76 mother and very low birth weight newbornpairs and collected oral, rectal, inguinal, hand and oral samples from newborns and vaginal and rectal cultures from their mothers. C. albicans isolates were identified by germ tube production and the remaining isolates were identified by the RapidID yeast plus system. Infants born vaginally ( $35 \%$ of which were colonized) rather than born by $\mathrm{C}$-section (only $10 \%$ were colonized) were at increased risk for early colonization ( $p=0.009)$ and $41 \%$ of the infants shared the same genotype of $C$. albicans with their mothers. Filippidi et al. [42] studied a group of 347 motherinfant pairs by collecting vaginal (mother) and oral and rectal swabs (infants). They concluded that the vast majority of colonized neonates were born vaginally and that large quantities of $C$. albicans colonies in the neonate may be correlated with Candida colony counts in the mother's vagina. The pulsotype of $C$. albicans was identical between all pairs of mother-infant, contrarily to what was found between mother and infant in the study by Caramalac et al. [39]. Siavoshi et al. [50] gathered oral and vaginal swabs from 108 mothers and 89 neonates, finding a significantly higher frequency of oral yeasts isolated from vaginallydelivered neonates than from $\mathrm{C}$-section delivered neonates $(p<0.01)$.

Conversely, two recent studies presented dissimilar results. Firstly, a study by Stecksen-Blicks et al. [51] collected swabs from cheeks and the tongue from 100 toddlers. Delivery mode was not associated with oral Candida colonization of the child at four weeks of age $(p>0.05)$. Exposure to furry pets and siblings, however, impacted oral Candida colonization: the presence of a sibling positively impacted candidal colonization but only at twelve months of age $(p<0.05)$, with almost all colonized infants having a sibling, while having a pet, at three months of age, was related to a lower Candida colonization ( $p<0.05)$. Furthermore, Ward et al. [53] studied 17 infants and 16 mothers and clustered swabs from the oral mucosa, forehead, and anal cavity of 
infants and from vaginal and anal sites of mothers implying next-generation sequencing. For the oral mycobiome, neither the alpha diversity trajectory over time $(p>0.05)$ nor beta diversity clustering $(P=0.261)$ were influenced by the delivery mode. Nevertheless, it is noteworthy that Csection born infants had a significantly higher relative abundance of oral Candida orthopsilosis than infants born vaginally $(p=0.001)$. Curiously, the authors suggest that this difference could be due to antibiotic intake influencing interkingdom relations. Of notice is that this last study used a very different assessment technology from the previous studies and a very low number of mother/child pairs.

\section{ISOLATED FUNG|}

Regarding the identification of oral fungi isolated, C. albicans was the most frequently isolated species in numerous studies [35, 37, 41, 42, 44, 53-56]. Other frequently isolated species included Candida parapsilosis [37, 41, 44, 53-56] Candida tropicalis [37, 53-55], Candida krusei [44, 55], Candida kefyr, Candida famata [44], Candida glabrata [55], Candida orthopsilosis, Saccharomyces cerevisiae, and Cladosporium velox [53]. Farmaki et al. [55] reported the colonization by Trichosporon $s p . \quad(\mathrm{N}=1)$ and Candida guilliermondii $(\mathrm{N}=1)$ and three newborns colonized by two yeasts simultaneously (C. albicans and C. glabrata; C. albicans and Trichosporon sp.; C. tropicalis and C. Iusitaniae). Caramalac et al. [39] reported that Candida guilliermondii was the predominant colonizer in newborns, followed by $C$. albicans, albeit this tendency changed during the second week of life, during which predominance of C. albicans in vaginally delivered newborns was evident. Rhodotorula rubra was only isolated in C-section delivered newborns [39]. It is noteworthy that, in the recent study by Ward et al., the authors highlight that $C$. orthopsilosis was previously characterized as $C$. parapsilosis due to morphological similarities of the two species [53]. This similarity could have misled previous researchers on the subject who based their works on traditional microbiological methods.

As for the C. albicans biotypes, Matee et al. [46] found more frequently the biotypes J1S (19.5\%), A1S (16.0\%) and J1R (14.5\%). Overall, the prevalence of different fungi isolated and identified may be biased due to the methods employed in each study. The selected papers presented heterogeneous methodology and limited equipment to broadly identify fungal species. Only one paper [53] described a powerful and contemporaneous identification technique (Illumina MiSeq) using an ITS (internal transcribed spacer) region primer (ITS2) and there is a clear lack of research, and consequently of literature, on the subject. More studies using wide-ranged identification tools, such as NGS (next generation sequencing), are required.

\section{DISCUSSION}

Microbiome acquisition in the newborn may represent a crucial process for the microbiome dynamic organization during adulthood. Firstly, our results from the literature review show that delivery mode might be associated with a higher carriage of oral fungi in young age (Figure 2) and, on the other hand, in the light of our results, the type of diet of the infant (formula-fed or breast-fed infants) does not seem to have impact on oral yeast carriage, although it is currently recognized that fungi are present in human breastmilk [57]. These results may be explained by the antimicrobial factors of the human milk influencing the oral ecology [58], although further studies are necessary.

Throughout life, the prevalence of fungi varies according to the age group. It is currently recognized that the set of primary oral colonizers strongly influences subsequent colonization, which may lead to more complex and stable ecosystems during adulthood $[6,59]$. In this way, the first microbial communities play a fundamental role in the development of the adult microbiota $[5,6]$. Immediately after birth, the new born is in contact with a wide variety of microorganisms and can be more easily colonized by maternal microorganisms due to its antigenic tolerance state [60, 61]. Therefore, there is a possibility of vertical microbial transmission of vaginal fungi to the newborn since these are normal colonizers of the vaginal microbiome [62]. Fungi not only contribute with their large cell size and their ability to generate filamentous hyphae to the biofilm structure, but also stimulate the immune system with distinct immunological consequences, helping developing the immune system of the host [26].

The human oral mycobiome includes a great diversity of fungi, however Candida is the most prevalent $[35,37$, $41,42,44,53,54]$. C. albicans was identified in each paper selected for this systematic review, being acknowledged as one of the early colonizers; however, its role in the oral ecosystem is still poorly understood. Moreover, in the literature, the prevalence of fungi in the oral cavity is not consensual. From our review, we verified a lack of studies

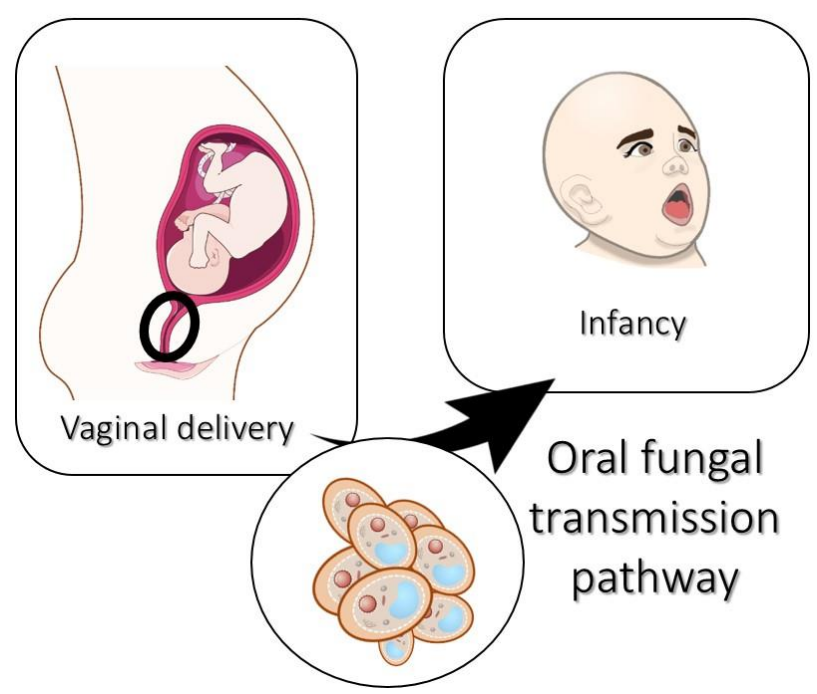

FIGURE 2: Mother-to-child-transmission during vaginal delivery. The figure was partially created using images from Servier Medical Art by Servier, which is licensed under a Creative Commons Attribution 3.0 Unported License; https://smart.servier.com. 
in this field and a methodological heterogeneity regarding the assessment and identification of the fungal oral microbiota. In addition, most of the methods applied were traditional microbiological methods which, due to their low sensitivity, may preclude the identification of the low prevalence fungi [32]. It is, therefore, important to carry out future studies using more sensitive methods, as reported by Monteiro-da-Silva [33], or molecular biology techniques [32].

\section{CONCLUSION}

Although there is still controversy regarding the influence of the delivery and feeding mode in the acquisition of the oral mycobiome, our results suggest that delivery mode influences the oral yeast carriage in childhood, specifically, vaginal delivery appears to promote oral yeast carriage (Figure 2). On the other hand, maternal breast feeding does not seem to influence oral mycology. More longitudinal studies with comparable sampling, analysis protocols and broad-spectrum identification methods must be performed to have a deeper insight on the underpinning mechanisms of fungal transmission, colonization and the repercussions of the early mycobiome later in life.

\section{ACKNOWLEDGMENTS}

Maria Azevedo is financed by Fundação para a Ciência e a Tecnologia/Ministério da Ciência, Tecnologia e Ensino Superior (FCT) SFRH/BD/144982/2019. This work was financed by FEDER - Fundo Europeu de Desenvolvimento

\section{REFERENCES}

1. Ding T, Schloss PD (2014). Dynamics and associations of microbial community types across the human body. Nature 509(7500): 357-360. doi: 10.1038/nature13178

2. Huttenhower C, Gevers D, Knight R, Abubucker S, Badger JH, Chinwalla AT, Creasy HH, Earl AM, FitzGerald MG, Fulton RS, Giglio MG, Hallsworth-Pepin K, Lobos EA, Madupu R, Magrini V, Martin JC, Mitreva $M$, Muzny DM, ..., White $O$ (2012). Structure, function and diversity of the healthy human microbiome. Nature 486(7402): 207-214. doi: $10.1038 /$ nature11234

3. Tamburini S, Shen N, Wu HC, Clemente JC (2016). The microbiome in early life: implications for health outcomes. Nat Med 22(7): 713722. doi: $10.1038 / \mathrm{nm} .4142$

4. DeWeerdt S (2018). How baby's first microbes could be crucial to future health. Nature 555(7695): S18-S19. doi: 10.1038/d41586-01802480-6

5. Sampaio-Maia B, Caldas IM, Pereira ML, Perez-Mongiovi D, Araujo R (2016). The Oral Microbiome in Health and Its Implication in Oral and Systemic Diseases. Adv Appl Microbiol 97: 171-210. doi: 10.1016/bs.aambs.2016.08.002

6. Sampaio-Maia B, Monteiro-Silva F (2014). Acquisition and maturation of oral microbiome throughout childhood: An update. Dent Res J 11(3): 291-301. PMID: 25097637

7. Dominguez-Bello MG, Costello EK, Contreras M, Magris M, Hidalgo $\mathrm{G}$, Fierer N, Knight R (2010). Delivery mode shapes the acquisition and structure of the initial microbiota across multiple body habitats in newborns. Proc Natl Acad Sci U S A 107(26): 11971-11975. doi: 10.1073/pnas.1002601107
Regional funds through the COMPETE 2020 - Operacional Programme for Competitiveness and Internationalisation (POCI), Portugal 2020, and by Portuguese funds through FCT in the framework of the projects PTDC/MEC$\mathrm{MCl} / 29777 / 2017$ and POCl-01-0145-FEDER-007274. Also this article is a result of the project NORTE-01-0145-FEDER000012, supported by Norte Portugal Regional Operational Programme (NORTE 2020), under the PORTUGAL 2020 Partnership Agreement, through the European Regional Development Fund (ERDF).

\section{CONFLICT OF INTEREST}

The authors certify that they have no affiliations with or involvement in any organization or entity with any financial interest or non-financial interest in the subject matter or materials discussed in this manuscript.

\section{COPYRIGHT}

(C) 2020 Azevedo et al. This is an open-access article released under the terms of the Creative Commons Attribution (CC BY) license, which allows the unrestricted use, distribution, and reproduction in any medium, provided the original author and source are acknowledged.

Please cite this article as: Maria Joao Azevedo, Maria de Lurdes Pereira, Ricardo Araujo, Carla Ramalho, Egija Zaura and Benedita Sampaio-Maia (2020). Influence of delivery and feeding mode in oral fungi colonization - a systematic review. Microbial Cell 7(2): 36-45. doi: 10.15698/mic2020.02.706

8. Power ML, Quaglieri C, Schulkin J (2017). Reproductive Microbiomes: A New Thread in the Microbial Network. Reprod Sci 24(11): 1482-1492. doi: 10.1177/1933719117698577

9. Lif Holgerson P, Harnevik L, Hernell O, Tanner AC, Johansson I (2011). Mode of birth delivery affects oral microbiota in infants. J Dent Res 90(10): 1183-1188. doi: 10.1177/0022034511418973

10. Chu DM, Ma J, Prince AL, Antony KM, Seferovic MD, Aagaard KM (2017). Maturation of the infant microbiome community structure and function across multiple body sites and in relation to mode of delivery. Nat Med 23(3): 314-326. doi: 10.1038/nm.4272

11. Li Y, Caufield PW, Dasanayake AP, Wiener HW, Vermund SH (2005). Mode of delivery and other maternal factors influence the acquisition of Streptococcus mutans in infants. J Dent Res 84(9): 806 811. doi: $10.1177 / 154405910508400905$

12. Pattanaporn K, Saraithong $P$, Khongkhunthian S, Aleksejuniene J, Laohapensang P, Chhun N, Chen Z, Li Y (2013). Mode of delivery, mutans streptococci colonization, and early childhood caries in three- to five-year-old Thai children. Community Dent Oral Epidemiol 41(3): 212-223. doi: 10.1111/cdoe.12013

13. Thakur R, Singh MG, Chaudhary S, Manuja N (2012). Effect of mode of delivery and feeding practices on acquisition of oral Streptococcus mutans in infants. Int J Paediatr Dent 22(3): 197-202. doi: 10.1111/j.1365-263X.2011.01176.x

14. Ubeja RG, Bhat C (2016). Mode of Delivery and Its Influence on the Acquisition of Streptococcus mutans in Infants. Int J Clin Pediatr Dent 9(4): 326-329. doi: 10.5005/jp-journals-10005-1386 
15. Gomez-Gallego C, Collado MC, Perez G, llo T, Jaakkola UM, Bernal MJ, Periago MJ, Frias R, Ros G, Salminen S (2014). Resembling breast milk: influence of polyamine-supplemented formula on neonatal BALB/cOlaHsd mouse microbiota. Br J Nutr 111(6): 1050-1058. doi: 10.1017/S0007114513003565

16. Cabrera-Rubio R, Collado MC, Laitinen K, Salminen S, Isolauri E, Mira A (2012). The human milk microbiome changes over lactation and is shaped by maternal weight and mode of delivery. Am J Clin Nutr 96(3): 544-551. doi: 10.3945/ajcn.112.037382

17. Al-Shehri SS, Sweeney EL, Cowley DM, Liley HG, Ranasinghe PD, Charles BG, Shaw PN, Vagenas D, Duley JA, Knox CL (2016). Deep sequencing of the $16 \mathrm{~S}$ ribosomal RNA of the neonatal oral microbiome: a comparison of breast-fed and formula-fed infants. Sci Rep 6: 38309. doi: 10.1038/srep38309

18. Hunt KM, Foster JA, Forney LJ, Schutte UM, Beck DL, Abdo Z, Fox LK, Williams JE, McGuire MK, McGuire MA (2011). Characterization of the diversity and temporal stability of bacterial communities in human milk. PLoS One 6(6): e21313. doi: 10.1371/journal.pone.0021313

19. Biagi E, Quercia S, Aceti A, Beghetti I, Rampelli S, Turroni S, Faldella G, Candela M, Brigidi P, Corvaglia L (2017). The Bacterial Ecosystem of Mother's Milk and Infant's Mouth and Gut. Front Microbiol 8: 1214. doi: 10.3389/fmicb.2017.01214

20. Dave V, Street K, Francis S, Bradman A, Riley L, Eskenazi B, Holland $N$ (2016). Bacterial microbiome of breast milk and child saliva from low-income Mexican-American women and children. Pediatr Res 79(6): 846-854. doi: 10.1038/pr.2016.9

21. Holgerson PL, Vestman NR, Claesson R, Ohman C, Domellof $M$, Tanner AC, Hernell O, Johansson I (2013). Oral microbial profile discriminates breast-fed from formula-fed infants. J Pediatr Gastroenterol Nutr 56(2): 127-136. doi: 10.1097/MPG.0b013e31826f2bc6

22. Avila WM, Pordeus IA, Paiva SM, Martins CC (2015). Breast and Bottle Feeding as Risk Factors for Dental Caries: A Systematic Review and Meta-Analysis. PloS one 10(11): e0142922-e0142922. doi: 10.1371/journal.pone.0142922

23. Pannaraj PS, Li F, Cerini C, Bender JM, Yang S, Rollie A, Adisetiyo H, Zabih S, Lincez PJ, Bittinger K, Bailey A, Bushman FD, Sleasman JW, Aldrovandi GM (2017). Association Between Breast Milk Bacterial Communities and Establishment and Development of the Infant Gut Microbiome. JAMA Pediatrics 171(7): 647-654. doi: 10.1001/jamapediatrics.2017.0378

24. Lewis ZT, Mills DA (2017). Differential Establishment of Bifidobacteria in the Breastfed Infant Gut. Nestle Nutr Inst Workshop Ser 88: 149-159. doi: 10.1159/000455399

25. Krom BP, Kidwai S, Ten Cate JM (2014). Candida and other fungal species: forgotten players of healthy oral microbiota. J Dent Res 93(5): 445-451. doi: 10.1177/0022034514521814

26. Baker JL, Bor B, Agnello M, Shi W, He X (2017). Ecology of the Oral Microbiome: Beyond Bacteria. Trends Microbiol 25(5): 362-374. doi: 10.1016/j.tim.2016.12.012

27. O'Donnell LE, Millhouse E, Sherry L, Kean R, Malcolm J, Nile CJ, Ramage $G$ (2015). Polymicrobial Candida biofilms: friends and foe in the oral cavity. FEMS Yeast Res 15(7): fov077. doi: 10.1093/femsyr/fov077

28. Pereira D, Seneviratne C, Koga-Ito C, Samaranayake L (2018). Is the oral fungal pathogen Candida albicans a cariogen? Oral Dis 24(4): 518526. doi: 10.1111/odi.12691

29. Morse DJ, Wilson MJ, Wei X, Bradshaw DJ, Lewis MAO, Williams DW (2019). Modulation of Candida albicans virulence in in vitro biofilms by oral bacteria. Lett Appl Microbiol 68(4): 337-343. doi: 10.1111/lam.13145.
30. Harriott MM, Noverr MC (2009). Candida albicans and Staphylococcus aureus form polymicrobial biofilms: effects on antimicrobial resistance. Antimicrob Agents Chemother 53(9): 3914-3922. doi: 10.1128/AAC.00657-09

31. Dupuy AK, David MS, Li L, Heider TN, Peterson JD, Montano EA Dongari-Bagtzoglou A, Diaz PI, Strausbaugh LD (2014). Redefining the human oral mycobiome with improved practices in amplicon-based taxonomy: discovery of Malassezia as a prominent commensal. PLoS One 9(3): e90899. doi: 10.1371/journal.pone.0090899

32. Ghannoum MA, Jurevic RJ, Mukherjee PK, Cui F, Sikaroodi M, Naqvi A, Gillevet PM (2010). Characterization of the oral fungal microbiome (mycobiome) in healthy individuals. PLoS Pathog 6(1): e1000713. doi: 10.1371/journal.ppat.1000713

33. Monteiro-da-Silva F, Araujo R, Sampaio-Maia B (2014). Interindividual variability and intraindividual stability of oral fungal microbiota over time. Med Mycol 52(5): 498-505. doi: 10.1093/mmy/myu027

34. Monteiro-da-Silva F, Sampaio-Maia B, Pereira Mde L, Araujo R (2013). Characterization of the oral fungal microbiota in smokers and non-smokers. Eur J Oral Sci 121(2): 132-135. doi: 10.1111/eos.12030

35. Neves A, Lobo L, Pinto K, Pires E, Requejo M, Maia L, Antonio A (2015). Comparison between Clinical Aspects and Salivary Microbial Profile of Children with and without Early Childhood Caries: A Preliminary Study. J Clin Pediatr Dent 39(3): 209-214. doi: 10.17796/10534628-39.3.209

36. Alteras I, Aryeli J (1980). The incidence of Candida albicans in the last day of pregnancy and the first days of the new born. Mycopathologia 72(2): 85-87. doi: 10.1007/bf00493816

37. Baley JE, Kliegman RM, Boxerbaum B, Fanaroft AA (1986). Fungal Colonization in the Very Low Birth Weight Infant. Pediatrics 78(2): 225-232. PMID: 3526268

38. Bliss JM, Basavegowda KP, Watson WJ, Sheikh AU, Ryan RM (2008). Vertical and Horizontal Transmission of Candida albicans in Very Low Birth Weight Infants Using DNA Fingerprinting Techniques. Pediatr Infect Dis J 27(3): 231-235. doi: 10.1097/INF.0b013e31815bb69d

39. Caramalac DA, da Silva Ruiz L, de Batista GC, Birman EG, Duarte M, Hahn R, Paula CR (2007). Candida isolated from vaginal mucosa of mothers and oral mucosa of neonates: occurrence and biotypes concordance. Pediatr Infect Dis J 26(7): 553-557. doi: 10.1097/INF.0b013e31806166d7

40. Chow BD, Reardon JL, Perry EO, Laforce-Nesbitt SS, Tucker R, Bliss JM (2016). Host Defense Proteins in Breast Milk and Neonatal Yeast Colonization. J Hum Lact 32(1): 168-173. doi: 10.1177/0890334415592402

41. Darwazeh AM, al-Bashir A (1995). Oral candidal flora in healthy infants. J Oral Pathol Med 24(8): 361-364. doi: 10.1111/j.16000714.1995.tb01200.x

42. Filippidi A, Galanakis E, Maraki S, Galani I, Drogari-Apiranthitou M, Kalmanti M, Mantadakis E, Samonis $G$ (2014). The effect of maternal flora on Candida colonisation in the neonate. Mycoses 57(1): 43-48. doi: 10.1111/myc.12100

43. Gabriel I, Olejek A, Stencel-Gabriel K, Wielgos M (2018). The influence of maternal vaginal flora on the intestinal colonization in newborns and 3-month-old infants. J Matern Fetal Neonatal Med 31(11): 1448-1453. doi: 10.1080/14767058.2017.1319352

44. Kadir T, Uygun B, Akyuz S (2005). Prevalence of Candida species in Turkish children: relationship between dietary intake and carriage. Arch Oral Biol 50(1): 33-37. doi: 10.1016/j.archoralbio.2004.07.004

45. Leibovitz E, Livshiz-Riven I, Borer A, Taraboulos-Klein T, Zamir O, Shany E, Melamed R, Rimon O-F, Bradenstein R, Chodick G, Golan A 
(2013). A prospective study of the patterns and dynamics of colonization with Candida spp. in very low birth weight neonates. Scand J Infect Dis 45(11): 842-848. doi: 10.3109/00365548.2013.814150

46. Matee MI, Samaranayake LP, Scheutz F, Simon E, Lyamuya EF, Mwinula J (1996). Biotypes of oral Candida albicans isolates in a Tanzanian child population. APMIS 104(9): 623-628. PMID: 8972686

47. Pinhat EC, Borba MGS, Ferreira ML, Ferreira MA, Fernandes RK, Nicolaou SK, Okamoto CT, O. Neto CF (2012). Colonização fúngica em recém-natos de muito baixo peso: um estudo de coorte. J Pediatr 88 : 211-216. doi: 10.2223/JPED.2192

48. Ross JM, Needham JR (1980). Genital flora during pregnancy and colonization of the newborn. J R Soc Med 73(2): 105-110. doi: 10.1177/014107688007300205

49. Schei K, Avershina E, Oien T, Rudi K, Follestad T, Salamati S, Odegard RA (2017). Early gut mycobiota and mother-offspring transfer. Microbiome 5(1): 107. doi: 10.1186/s40168-017-0319-x

50. Siavoshi F, Taghikhani A, Malekzadeh R, Sarrafnejad A, Kashanian M, Jamal AS, Saniee P, Sadeghi S, Sharifi AH (2013). The Role of Mother's Oral and Vaginal Yeasts in Transmission of Helicobacter Pylori to Neonates. Arch Iran Med 16(5): 0-0. doi: 013165/AIM.009

51. Stecksen-Blicks C, Granstrom E, Silfverdal SA, West CE (2015). Prevalence of oral Candida in the first year of life. Mycoses 58(9): 550556. doi: $10.1111 /$ myc. 12355

52. Waggoner-Fountain LA, Walker MW, Hollis RJ, Pfaller MA, Ferguson JE, 2nd, Wenzel RP, Donowitz LG (1996). Vertical and horizontal transmission of unique Candida species to premature newborns. Clin Infect Dis 22(5): 803-808. doi: doi: 10.1093/clinids/22.5.803

53. Ward TL, Dominguez-Bello MG, Heisel T, Al-Ghalith G, Knights D, Gale CA (2018). Development of the Human Mycobiome over the First Month of Life and across Body Sites. mSystems 3(3): e00140-17. doi: 10.1128/mSystems.00140-17

54. Zöllner MSAdC, Jorge AOC (2003). Candida spp. occurrence in oral cavities of breastfeeding infants and in their mothers' mouths and breasts. Braz Oral Res 17: 151-155. doi: 10.1590/s151774912003000200010
55. Farmaki E, Evdoridou J, Pouliou T, Bibashi E, Panagopoulou $P$, Filioti J, Benos A, Sofianou D, Kremenopoulos G, Roilides E (2007). Fungal colonization in the neonatal intensive care unit: risk factors, drug susceptibility, and association with invasive fungal infections. Am J Perinatol 24(2): 127-135. doi: 10.1055/s-2007-970078

56. Mattos-Graner RO, de Moraes AB, Rontani RM, Birman EG (2001). Relation of oral yeast infection in Brazilian infants and use of a pacifier. ASDC J Dent Child 68(1): 33-36, 10. PMID: 11324404

57. Boix-Amoros A, Martinez-Costa C, Querol A, Collado MC, Mira A (2017). Multiple Approaches Detect the Presence of Fungi in Human Breastmilk Samples from Healthy Mothers. Sci Rep 7(1): 13016. doi: 10.1038/s41598-017-13270-x

58. Timby N, Domellof M, Holgerson PL, West CE, Lonnerdal B, Hernell O, Johansson I (2017). Oral Microbiota in Infants Fed a Formula Supplemented with Bovine Milk Fat Globule Membranes - A Randomized Controlled Trial. PLoS One 12(1): e0169831. doi: 10.1371/journal.pone.0169831

59. Gronlund MM, Lehtonen OP, Eerola E, Kero P (1999). Fecal microflora in healthy infants born by different methods of delivery: permanent changes in intestinal flora after cesarean delivery. J Pediatr Gastroenterol Nutr 28(1): 19-25. Doi: 10.1097/00005176-19990100000007

60. Mold JE, Michaelsson J, Burt TD, Muench MO, Beckerman KP Busch MP, Lee TH, Nixon DF, McCune JM (2008). Maternal alloantigens promote the development of tolerogenic fetal regulatory $T$ cells in utero. Science 322(5907): 1562-1565. doi: 10.1126/science. 1164511

61. Zaura E, Nicu EA, Krom BP, Keijser BJ (2014). Acquiring and maintaining a normal oral microbiome: current perspective. Front Cell Infect Microbiol 4: 85. doi: 10.3389/fcimb.2014.00085

62. Bradford LL, Ravel J (2017). The vaginal mycobiome: A contemporary perspective on fungi in women's health and diseases. Virulence 8(3): 342-351. doi: 10.1080/21505594.2016.1237332 